\title{
Considering conceptual type
}

\author{
Nanna Bonde, \\ The Royal Danish Academy of Fine Arts, School of Architecture, Institute of Design and \\ Communication
}

\section{BECOMING CONSCIOUS}

In some ways, a type designer is like an author. In much the way that a text goes on living after leaving the hands of its author, the same can be said of a typeface when it leaves the hands of its designer. The type designer creates a range of choices. What they imply may not be fully grasped at the outset but at the same time, they ought to be acknowledged as being meaningful. Type is communicative. Even though this communication cannot be controlled, it should not be ignored. For instance, one interesting aspect of type-design is the continued influence of handwriting tools, among others, on letterforms. Type that mimes, for example, the brushstrokes of a quill is still being produced: the material effects of predecessors are replicated in instances where this materiality is no longer present. This is due to tradition but also due to the fact that what is being replicated are not merely arbitrary material traces but the meaning one associates with a given materiality, that it to say, its connotative power.

This connotative power of type no longer goes as unnoticed as may once have been the case. In an article about the movie, Helvetica (Hustwit 2007), Ellen Lupton notes that:

“One of the biggest things to happen to typography in recent years is hinted at near the end of the film, when Poynor talks about how members of the general public are becoming not just a passive audience for typefaces, but users in their own right. 'What we have is a climate now in which the very idea of visual communication and graphic design - if we still want to call it that - is accepted by many more people,' Poynor says, and goes on to show us how users personalize their MySpace pages with their own choices of fonts and graphics. 'Those decisions you make become expressions of who you are'" (Lupton 2007).
A shift in type awareness is occurring. Awareness of the expressive aspect of type is no longer merely of interest to designers. It is becoming of concern to everyone. Branding is all-pervasive and type has become a tool for personal expression, whether it is of an individual, a corporation, a nation or some other entity aiming at expressing a certain identity. More and more people are becoming skilled in decoding the implications of type-choice. It follows that the use of type becomes meaning-ful to them. As type designers, or writers, you engage readers that are increasingly aware of what messages you are trying to send.

In branding and advertising, the use of type and typography is pretty much always carefully thought out and the growing number of corporate typefaces certainly speaks to the shift in type awareness. At the same time, in a lot of areas, the visuality of written language is still being used in what is primarily a conventional way. Sometimes, it is striking how great a discrepancy there is between how a text engages with the nature of language and how it presents its argument visually. Several instances of using typography expressively, in the sense of text arrangement, already exist, while other examples that consider the possibilities stemming from typeface choice - and make use of this expressive tool - are on the rise. Fiction is one area where we will certainly be experiencing further explorations as a consequence of the general shift in type awareness.

If you use type in a conventional way, you are still using it expressively. Perhaps you are using convention to your advantage. For instance, a novelist might want to convey a specific genre so that the reader will instantly be able to decode what kind of reading-strategy is required or implied. Just as you might want to disturb the reader-contract verbally, you might also imagine how you could achieve this visually, whether unintentionally or 
purposefully. For instance, you could use type to make a political message mimic a commercial one, or vice versa.

In this cultural landscape of expanded type awareness and possibilities, a consideration of the very nature - or role - of type takes on interesting implications. So does the concept of conceptual type.

\section{WHAT IS TYPE?}

As this is an exploration of conceptual type, it is relevant to delve into the definition of the term "type", since there are sometimes, in the field of typography, differing usages of terminology. The terms type and typography are often used interchangeably (see, e.g., Baines \& Haslam 2005, Willen \& Strals 2009). In Type \& Typography, Phil Baines and Andrew Haslam define typography thusly: “Typography: the mechanical notation and arrangement of language" (Baines \& Haslam 2005, p. 7). They further note, "typography means writing using repeatable units, lettering is unique" (ibid., p. 10). Those repeatable units are what is deemed type. Type designates the physical object; originally, it refers to moveable metal type. ${ }^{1}$ However, not all writing is type. The term "type", then, is generally used in a different sense than the term "lettering" (Baines \& Haslam 2005; Willen \& Straals 2009). Baines and Haslam set up this distinction: "The way lettering is distinguished from type is that it is the creation of letters that - regardless of

The distinction between lettering and type can be a blurry one. Take, for instance, the poster, "Oscillator", created by the design collective, Underware, the writing is based upon "Liza", a typeface made to resemble handlettering. The word-unit appears in such a way that the wording is ambiguous: it can be read as either yes or no. This is either a piece of type/typography or of lettering, depending upon whether it is in the coding of the font, and accordingly part of the design of the typeface, or whether the type is manipulated to achieve the form of the ambiguously written word for this specific instance. In either case, it conveys a meaning - or rather, several meanings.

(C) Jhoeko \& Underware whether they are designed for reproduction - are essentially 'special' and made for a specific purpose only. Type, however, was from the outset designed for duplication. Its units (individual letters) could be assembled to set a message, disassembled and reused to set other messages" (Baines \& Haslam 2005, p. 90). Pursuant to this argument, the difference is seated in the design process or perhaps, it might be said, in the intention behind the design. If I take a piece of original lettering and make a font from it, you could say that I am transferring the letterforms from the domain of lettering into the domain of type.

Now, since my present focus is on exploring the possibilities or potentials inherent in the concept of conceptual type, I find it appropriate to look at both type and lettering. Although there is an important difference between actually producing one or the other (and I will be commenting more on this in what follows), my understanding of the situation, on the level of interpretation and meaning, is that both instances can inform my exploration. In other words, I look at conceptuality with regard to design of letterforms, regardless of whether these are manifested as type or as a case of lettering; in either instance, the typeform has been created in order to convey something. This is also the case with regard to the "arrangement of language".

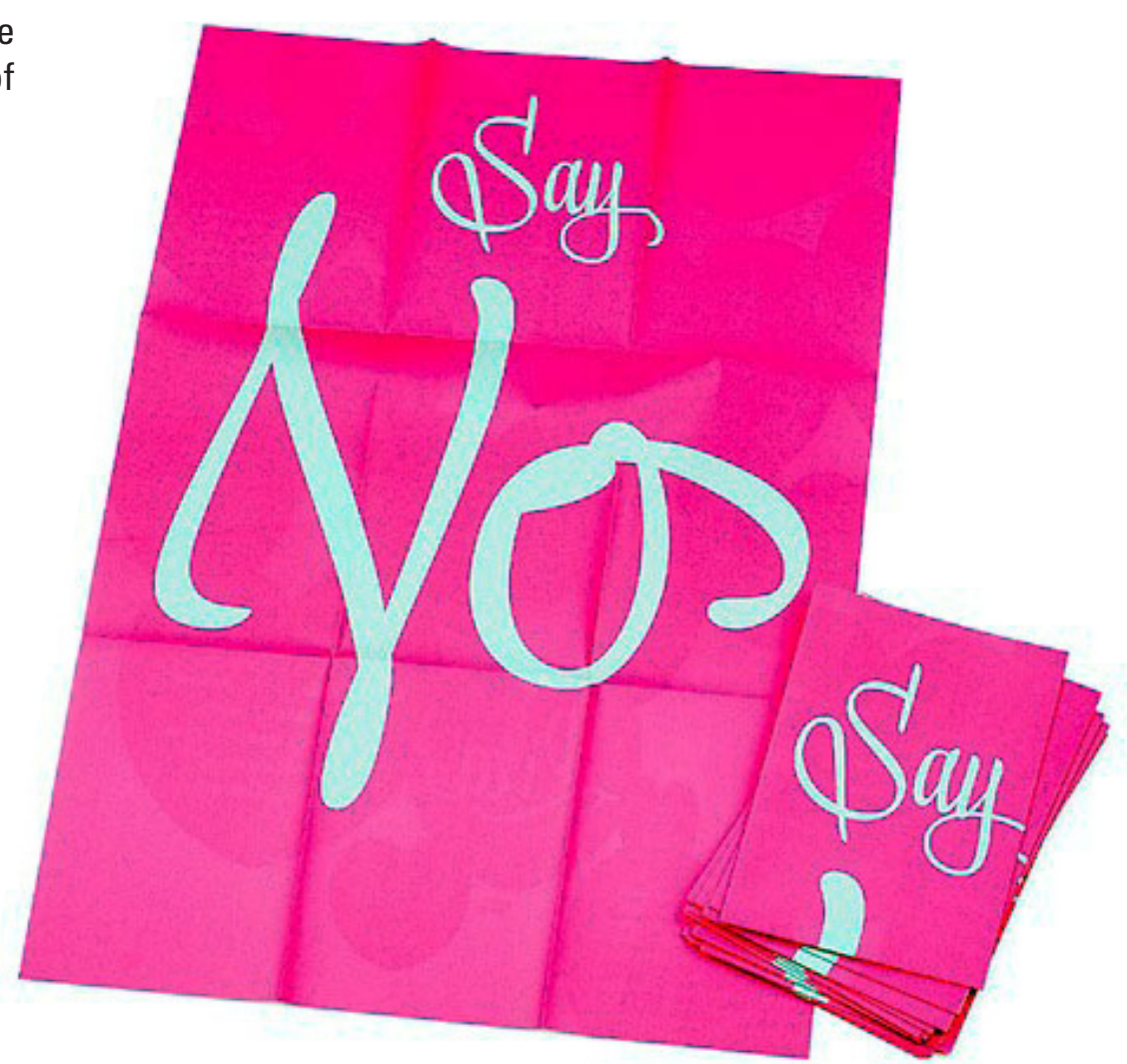




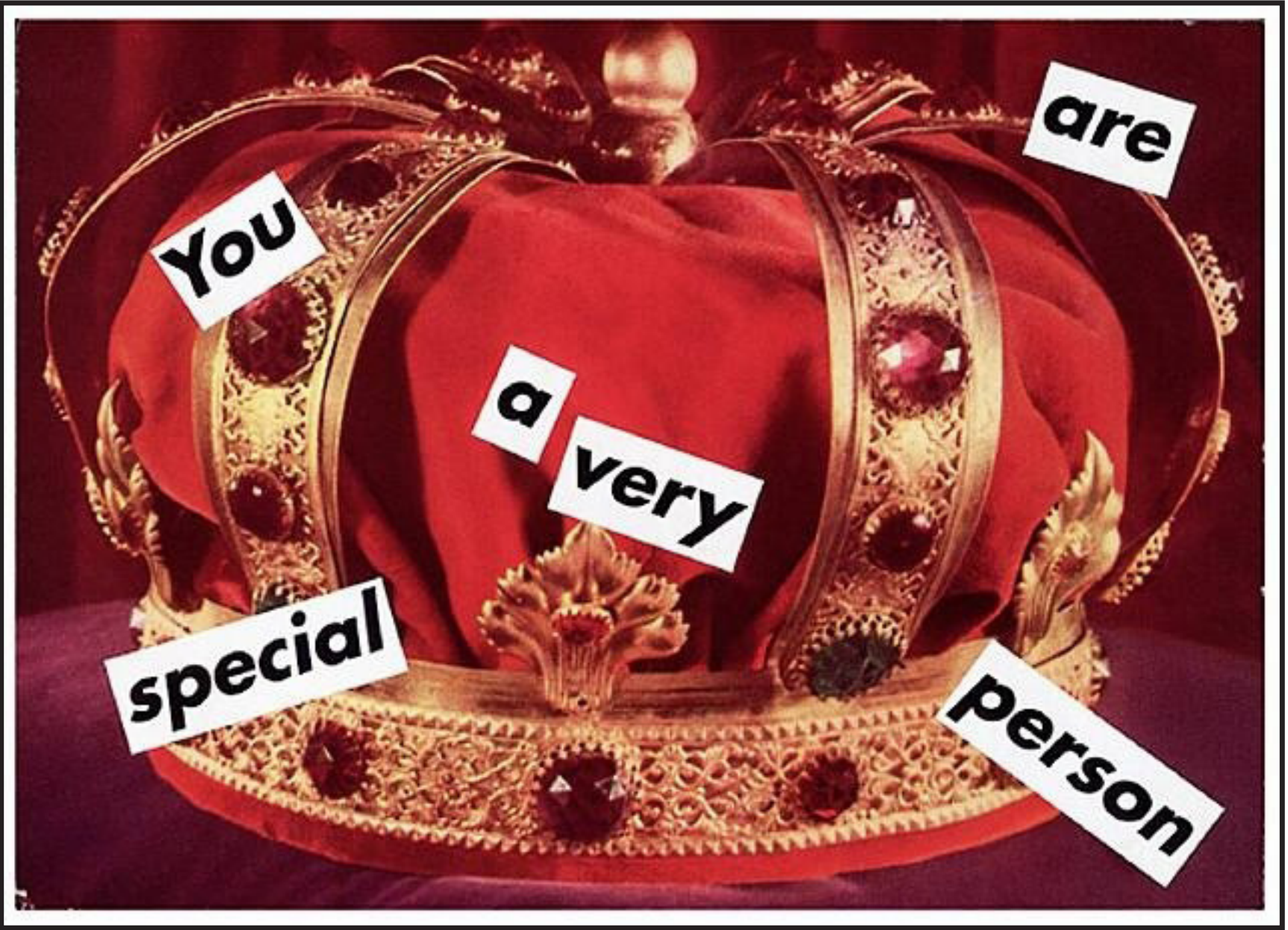

Barbara Kruger (1995), Untitled (You Are A Very Special Person). The artwork uses (a version of) Futura. When Paul Renner designed Futura in 1927, it was a typeface which, by virtue of its form, heralded the modernist style and was therefore, at that point in history, a politically loaded typeface. Obviously, today, its connotative power has changed but still it is part of a history that imbues current typefaces, or the current use of typefaces, with meaning.

Barbara Kruger: Untitled (You are a very special person) Collage, 13,6 x 19,1 cm

Courtesy Sprüth Magers Berlin London

Moreover, the distinction between typography, as writing that employs repeatable (type-)units, and lettering, which is made for one specific purpose, might not always be so easily drawn. For instance, when a font is designed and coded for purposes of allowing the individual characters to interact in differing ways with other characters, as is the case in "contextual alternates", the typographic setting of type starts to resemble lettering. So although I do not wish to bypass these distinctions, I will embrace both type/typography and lettering when endeavoring to exemplify how conceptual type might be used as a generative concept.

\section{THE LIFE OF TYPE}

Being a type designer often means that you have no influence on - and no knowledge of - what use the end product of your work will be put to and on this account, it also entails that you know nothing about the contextual elements of the eventual use situation. You might have an intention for the use of your product, of course, but whether this will coincide with the intention of the user is not a given. In the end, the type will be read, or interpreted, in different ways. One way of looking at the meaning of type, then, is to consider the design, or the form, of the typeface itself as being removed from an actual situation of use. In some ways, this can be regarded as the only way to really say something about the typeface, whether specifically or generally. However, it will certainly give rise to a very limited description. The meaning of a typeface, or rather the interpretation of it, is generated through a complex intermingling of constitutive factors. The typeface never actually exists in an unattached manner: it is always conditioned - physically, socially and historically. When looking at type in the proper situational context, an analysis of form will simply not suffice. Still, any interpretation of the meaning-potential of a given typeface is limited, as is the case with any other interpretation, if only 
because the interpreter is necessarily positioned again, physically, socially, historically. So, there are multiple approaches towards analyzing the meaning of type. Any one of them is bound to be partial; it is crucial to remember that this is the case.

There are instances of lettering that literally cannot be divorced from their context, which means that the interpretation of them typically takes on quite a different character than the interpretations of type that are sometimes offered. Focus on contextuality is something that I believe could be explored at greater length with regard to type. There are different ways of describing the active role of type in our culture: type as a visual phenomenon that expresses certain values; type as another level of meaning in written language; type as a cultural expression and as a personal expression, etc. When looking at type in context, one notices that meaning arises from a much broader set of parameters than the inherent characteristics of the typeface alone; these, incidentally, conjoin with other aspects of the use situation. This point of view entails that these characteristics cannot be regarded as stable entities in relation to their meaning-generating capacity. It is rather the case that they are in flux.

An interesting example of type analysis is to be found in the movie, Helvetica, a movie that, as stated on the website, "looks at the proliferation of one typeface... as part of a larger conversation about the way type affects our lives." ${ }^{2}$ This movie documents how a typeface, as much as any other artifact, has a wirkungsgeschichte ${ }^{3}$ and how looking at it from this perspective serves to initiate the uncovering of the vast meaning-potential it possesses. This wirkungsgeschichte, which can be translated roughly into "history of effects" or "effective history", speaks to the "connectedness" of the typeface, to how it is continuously influenced and to how it perpetually gives rise to effects, culturally. This story provides us with a much denser, and much messier, picture of the typeface. As I mentioned earlier on, each particular instance of story-telling is itself edited and is imbued with a particular optics. For example, in Helvetica, certain instances, rather than others, of the font in use have been selected. To put this in other words, the story of the typeface is mediated in a certain way. Furthermore, this particular mediation has now become part and parcel of the story.

Looking at the meaning of type from this perspective gives us an insight that destabilizes "meaning". When you interpret type as a meaning-generating entity, which is an integral part of a much wider contextual setting and therefore produces and gains meaning in accordance with this, you come to regard type as a cultural entity that cannot be stable in terms of meaning. Interpreting type in this way could be labeled a hermeneutic approach.

\section{APPROACHING THE CONCEPTUAL}

Having looked at the nature of type, I will now move on to consider the defining term, conceptual. Using a rather loose definition of the term, "conceptual", one might say that it simply signifies something that has a strong ideational foundation. However, in this sense, the term is rather weak and could be applied to most if not all instances of design, seeing as most design processes start out with a concept. Looking at the term, "conceptual", from the vantage point of conceptual art, then, could prove useful in order to delimit the term. With regard to conceptual art, there has been a lot of debate about what conceptual art actually is; this is a discussion that can certainly inform us and bring us closer to determining what "conceptual" might mean in relation to type.

The term, "conceptual art", might, in a narrow sense, designate the artworks that spring from the late twentieth century artistic movement ${ }^{4}$ or it might, in a broader sense, designate a particular approach to art-making that can be observed much earlier on, as well as later on, in art history. ${ }^{5}$ There are aspects that are generally agreed upon as being key denominators, though not constitutive factors, of conceptual art. Breaking with convention - by challenging the role of the artist, or to put it another way, by challenging the role of the relationship between the artist and the audience - is one such aspect; placing a question mark alongside the scope of the artwork, i.e. questioning what it is that constitutes an artwork, is another. Conceptual art is supposed to make us reflect by questioning the conventional boundaries of art. Indeed, a proclaimed aim of the conceptual art movement was to denounce the primacy of perception in art and to install the concept in that position, following the belief that the role of art was to make you reflect and that art would otherwise be obsolete.

In challenging conventions, one thing that is generally said to be characteristic of conceptual art is that it is not confined to specific media; in fact, it is often said to be rejective of traditional artistic media. Instead of setting out to create a specific kind of work, the conceptual artist develops an idea and executes this idea in whatever form best befits it. Hence, the saying that concept is primary 
and execution secondary or, in the most extreme rendition of this, that the idea is everything, is actually what constitutes "the art", whereas the execution, in effect, becomes superfluous. These two claims are, of course, divergent to some extent, since "secondary" does not imply that the execution is irrelevant or superfluous. One could easily argue that the physical manifestation certainly does become part of the artwork. In any case, this kind of detachment of idea from form isn't really translatable when it comes to type: although experiments of form and material are possible, type is ultimately confined to being the visual expression of an already given code, i.e., a conventional code.

However, the rejection of the traditional form is not an imperative. There are various ways of regarding conceptuality in relation to art. In Conceptual Revolutions in Twentieth-Century Art (2009), the author, David W. Galenson, posits a distinction between two types of artistic approach. Galenson speaks of conceptual innovators, artists who exhibit a certain artistic behavior, who violate existing artistic conventions, who are seen as reducing "style to a short-run strategy rather than a longrun goal" (Galenson 2009, p. 16). He opposes these conceptual innovators with experimental artists, the latter being those who pursue "aesthetic goals through the gradual development of a personal style." With this division posited according to the factor of behavior, he maps a history of conceptual in art which is different from the one that focuses on the conceptual art movement of the 1960s and 1970s and its opposition to the conventional form of the art object. ${ }^{6}$ Galenson's conception of the conceptual does not place the same emphasis on media, which when it comes to conceptual art would be connected with the use of non-traditional media, but places it instead on the artistic approach. This perspective, then, might prove to be more relevant when speaking of conceptual type.

\section{THE IDEA BECOMES A MACHINE}

In contrast to the way conceptual art is sometimes said to arise from a sequential division of concept construction followed by material execution, noting that materia/might merely imply being expressed in language, what I believe is that in relation to conceptual type design, you have to regard these modes or phases as being simultaneous or parallel events. However, the concept still remains vital: it is what will inform and delimit the design. It might still be regarded as a machine, ${ }^{7}$ albeit a machine that is under construction at the same time as it constructs.

Now the simultaneity of machine-construction and construction-of-machine points toward an important observation about the nature of being conceptual, in the manner I am speaking of here. Since the conceptual machine is not finished but is partly constructed by its construct, it cannot produce sameness; if it does so, it is no longer a conceptual machine but has morphed into something else. That is to say, a criterion of the conceptual could be that it inserts difference. A concept might be explored through different materializations, ${ }^{8}$ but exercising material experiments according to a given concept might not be tantamount to a conceptual approach, when the material, or one could say the stylistics, rather than the concept, comes to be the generating force. Distinguishing, as does Galenson, between the conceptual and the expressive might be one way of addressing this issue. However, in practice, such a distinction would certainly prove difficult to make.

The distinction between conceptual and expressive, however, is of importance if one wants conceptual type to be understood as type that crosses borders, i.e. that expands our notion of type. Shifting the focus from object to process, one that is perpetually evolving, points to an understanding that conceptual type should not be repetitive, and should not, in

\begin{abstract}
An official still from the movie, Helvetica, framing the typeface as an integral part of the cityscape. The face is so common that it, to some, has become the perfect embodiment of a "non-face", in the sense that it is "neutral", in the sense that it does not connote anything specific. But surely, it does, depending upon the contextual elements, one of which is the viewer. To this, one might add that since the launching of this documentary film, many viewers probably view the typeface differently than they did before.
\end{abstract}

Photo courtesy of Swiss Dots

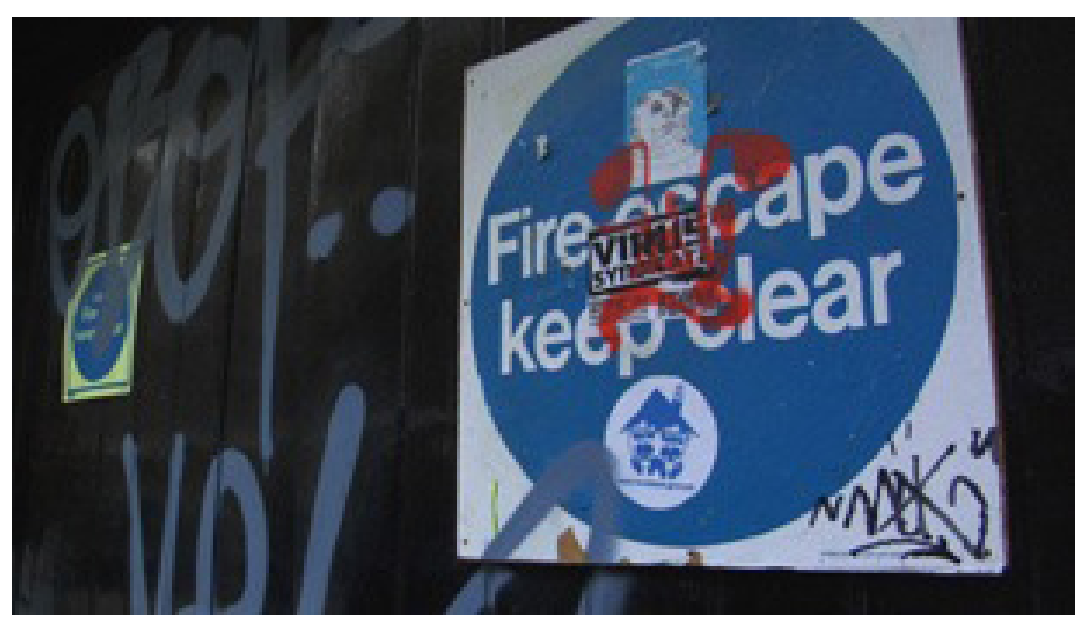




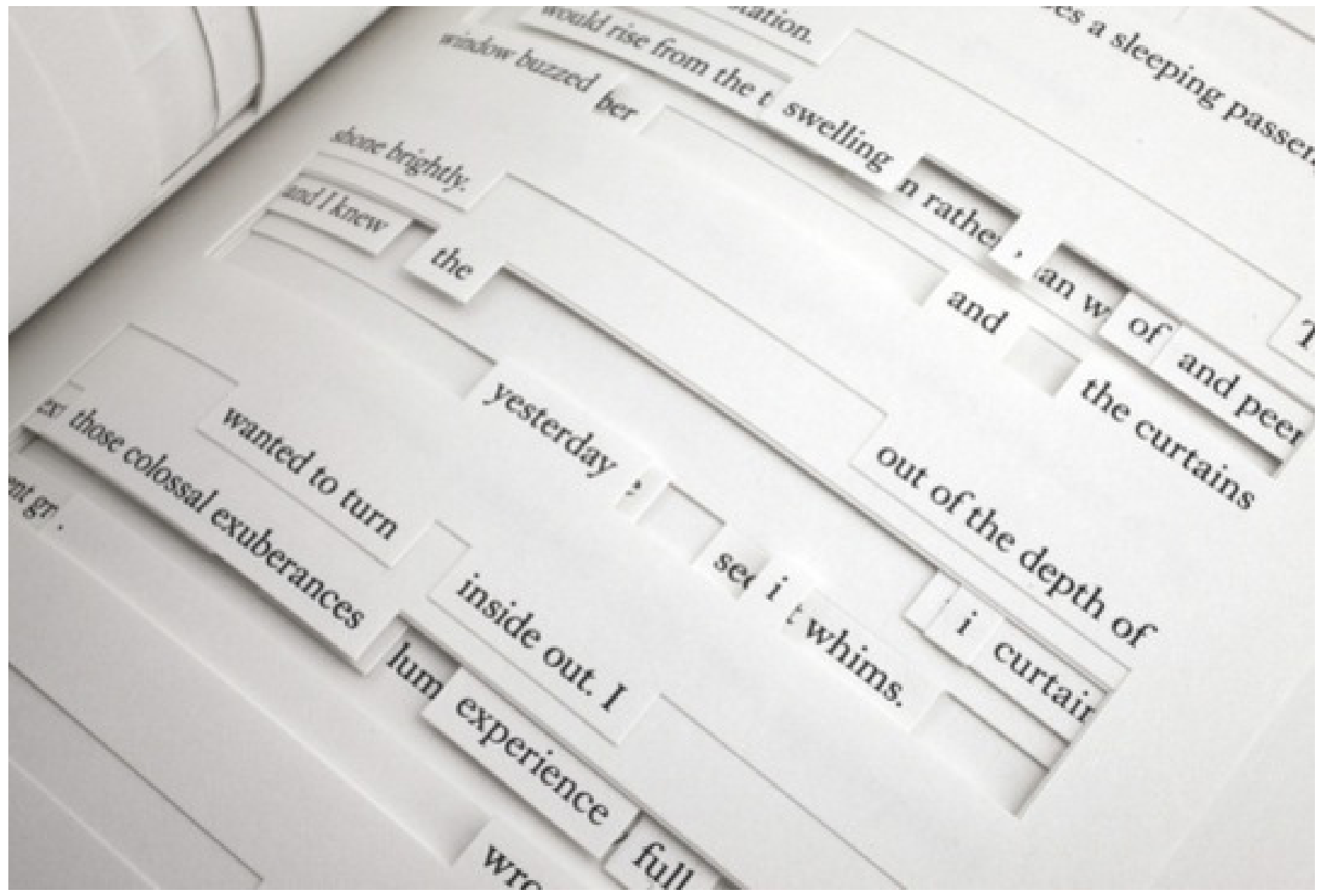

In Jonathan Safran Foer's novel, Tree of Codes (2010), a recent example of breaking with conventions of traditional media ${ }^{9}$, the book as physical artifact becomes an integral part of the telling of the story: the visual and the verbal become inseparable. The story is cut into and out of an existing text, ${ }^{10}$ thereby giving rise to a new one. The process is a kind of sculpting and this way of coming into existence is visually/physically materialized, so that, for one thing, it no longer makes sense to speak about typography as a separate aspect of the work. As Olafur Eliasson puts it, this is "a book that remembers that it actually has a body."11

\section{Courtesy of Visual Editions}

fact, ultimately put the concept first. It follows from this that conceptual type should accordingly not plainly repeat the movements of conceptual art. It might be the case that conceptual type could be deemed type that speaks to the meaning of type, that asks questions about the nature of type, in much the manner that conceptual art questions the boundaries of art.

\section{A BORDERLAND EXISTENCE}

Conceptual type is more than "type led by ideas" since all type, to some extent, is led by an idea of some sort. In other words, type may always be "conceptual" but depending on what definition of conceptual we are operating with, it will be so to various degrees. Therefore, I have tried to delimit the term, "conceptual", so that we might be able to use the concept of conceptual type in a meaningful and generative way. Also, I proclaimed the usefulness of provisionally disregarding the division between lettering and type. By this means, the focus of the exploration has not been trained on what type is but on what it does. I believe that a focus on the role of type and the possibilities and importance of type are what is of interest here.

Above I employed the concept, "wirkungsgeschichte" to explain how the "meaning" of a cultural product can be understood as unfolding or developing ceaselessly. And I have tried to emphasize how this might be informative for the field of type design. When we consider the meaning of type, we certainly gain insight by looking at a contextual totality instead of focusing on formal characteristics alone. I do not deem analyzing formal characteristics of type irrelevant. However, in order to gain an understanding of what type does, I contend that we need to take a look at the bigger picture. Looking at type as an instance of communication that is historically, socially and medially determined opens up for us a broader scope, which can inspire us to rethink the conventional understanding(s) of type, designer 


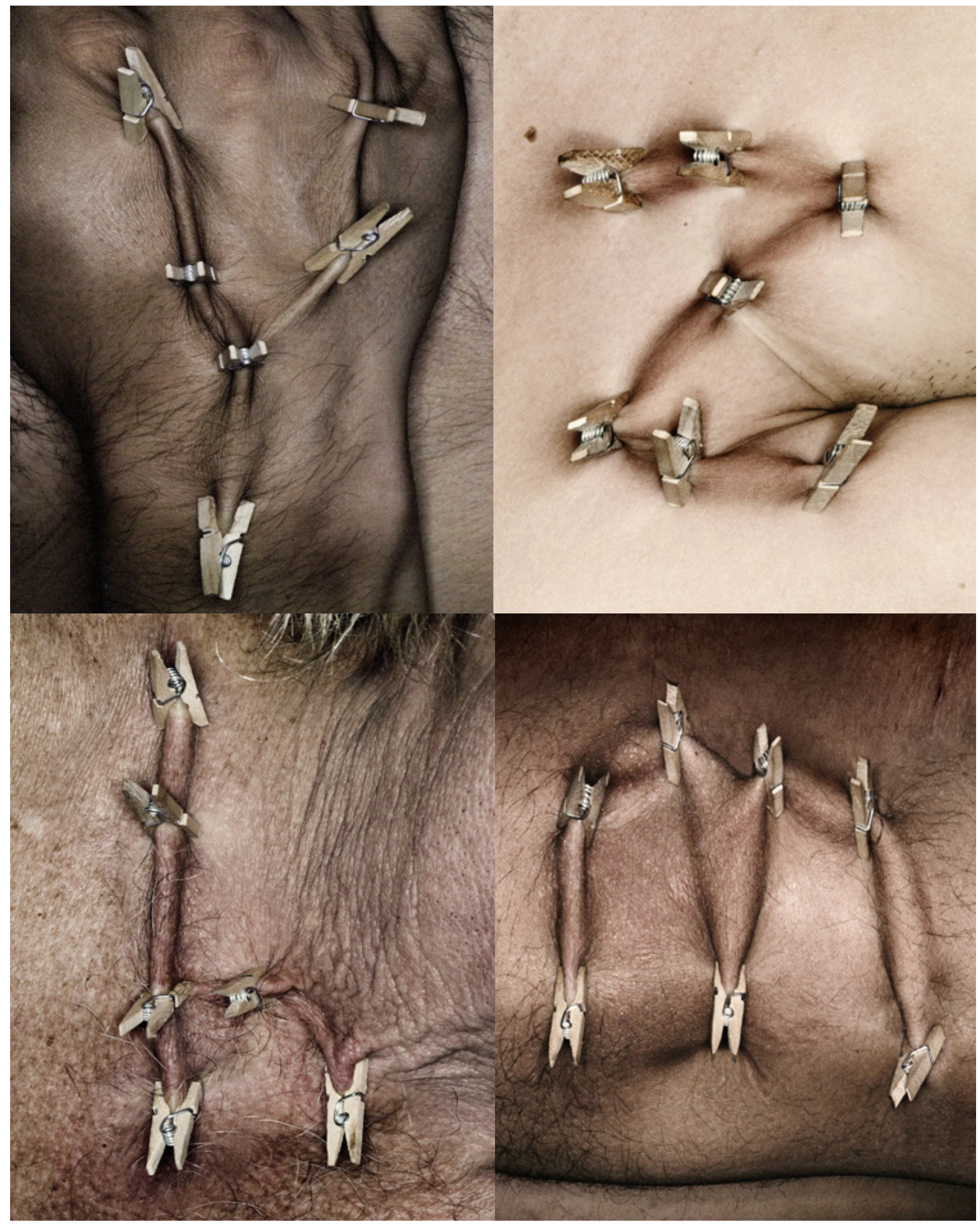

Writing on the body might signify how discourse, i.e. language, affects our lives and our bodies, inasmuch as we are bodily and discursively inscribed in the world. There are numerous different types of writing on the body and with the body. Might these fleshed out letters, from Thijs Verbeek's alfabet in huid (typeface in skin), speak to this corporeality of language and be deemed an instance of conceptual lettering? Or are they just a material experiment? Would they be more conceptual if they were scars?

Courtesy of Thijs Verbeek (concept and styling) \& Arjan Benning (photograpy) 
and user. Conceptual type, then, might be type that examines and/or exceeds the boundaries of the conventional, that is to say, the conventional understanding of these categories. You might say that this kind of type is self-referential in that it explores its own conditioning.

Type has such strong conventionality that challenging form and material quite easily serves to prod us to regard certain kinds of type as actually not being type: challenging our understanding of type is not all that difficult. However, not all type that falls outside neat categorization is necessarily conceptual, as can be witnessed through the distinction between expressive and conceptual type. To my mind, a lot of type experiments fall into the category of expressive rather than conceptual although, as I have pointed out, the distinction might not always be so easily drawn: the difference partly has to do with intention. Consider the "Oscillator" poster: whether a piece of type/typography or lettering, we could call it "expressive" if we take it as displaying a visual play on words, and if the font is taken as being an exploration into contextual alternates. Or we might call it a conceptual piece if we take it as speaking, by intent, to a more general ambiguity of language.

In the latter case, you could say that this was type that explored the embeddedness of type in language. Today, the general consensus is that the notion of "transparent" or "neutral" type is a fiction; in other words, the idea of type being merely a carrier of preconceived messages does not suffice anymore. Type always conveys something. It is a meaning-generating entity not only as a visual but also as a verbal feature. If you regard type as being a physical manifestation of language, it can be said to be situated in a sort of borderland, a place where the boundaries between the verbal and the visual are blurred. So rather than seeing type as a link between the verbal and the visual, one could regard it as a negation of this division. Taking this borderland position as a jumping-off point, conceptual type might be type that explores how type performs language. Analyzing what understanding of the nature of language lies behind certain type expressions is an area that holds a lot of potential for the understanding of the relation between type and language.

Conceptual type as type that performs the ambiguity of language or that performs a deconstruction of meaning, following a deconstructive understanding, has already been an approach furthering type experiments. Also, a pervasiveness of language
- following a post-structuralist contention that subjects are constituted through language or that language, in the very least, shapes us from the first instant we are in this world - might be seen, for example, as being explored in certain experiments dealing with inscribing the body. And again, whether or not we deem such experiments conceptual has to do with intent and process.

\section{NOTES}

1. "Type is the physical object, a piece of metal with a raised face at one end, containing the reversed image of a character." (Baines \& Haslam 2005: 6)

2. http://www.helveticafilm.com/about.html

3. The term stems from the German philosopher Hans-Georg Gadamer's philosophical hermeneutics.

4. Established in the 1960s by a number of artists who were rebelling against art being a commodity, by challenging the art-term, the role of the artist and the art institutions.

5. In the following, I adopt the latter definition and I will briefly lay out why this perspective is more relevant for the current purpose of examining what the term "conceptual" might mean in relation to type.

6. Partly being a critique of the hegemony of the visual in art, the movement links to the work of Marcel Duchamp appearing at the beginning of the twentieth century. The challenging of art institutions and of art being a commodity are also themes in common.

7. Referring to Sol LeWitt, “The idea becomes a machine that makes the art." LeWitt, Sol (1967): "Paragraphs on Conceptual Art", in: Artforum.

8. As Sol LeWitt once said, in regard to conceptual art, "For each work of art that becomes physical there are many variations that do not." LeWitt, Sol (1969): "Sentences on Conceptual Art", in: ArtLanguage: The Journal of Conceptual Art.

9. There are many, and earlier, examples of authors breaking with the conventions of the novel genre. Foer is a contemporary author who, in his work, explores borders in various ways.

10. Namely, Bruno Schulz's The Street of Crocodiles, the English translation of the original Sklepy Cynamonowe (The Cinnamon Shops) from 1934.

11. http://www.visual-editions.com/our-books/treeof-codes

\section{REFERENCES}

Baines, Phil, \& Haslam, Andrew. (2005). Type and Typography (2nd ed.). London: Laurence King.

Foer, Jonathan Safran, \& Schulz, Bruno. (2010). Tree of Codes. London: Visual Editions. 
Galenson, David, \& National Bureau of Economic Research. (2009). Conceptual Revolutions in TwentiethCentury Art. NBER working paper series no w15073. Retrieved from http://www.nber.org/papers/w15073

Hustwit, Gary (Director). (2007). Helvetica. Film website accessed December 7th, 2013, http://www.helveticafilm. com

Lupton, Ellen. (2007). Forever Helvetica. Metropolis Magazine. http://www.metropolismag.com/story/20070620/foreverhelvetica

LeWitt, Sol. (1967). Paragraphs on Conceptual art. Artforum, $5(10), 79-83$.

LeWitt, Sol. (1969). Sentences on Conceptual Art. ArtLanguage: The Journal of Conceptual Art.

Middendorp, Jan. (2004). Dutch Type. Rotterdam: 010.

Willen, Bruce, \& Strals, Nolen. (2009). Lettering \& Type (1st ed.). New York: Princeton Architectural Press.

\section{CORRESPONDENCE}

Nanna Bonde, The Royal Danish Academy of Fine Arts, School of Architecture, Institute of Design and Communication, Philip de Langes Allé 10, 1435 Copenhagen $\mathrm{K}$.

E-mail: nanna.nielsen@kadk.dk

Published online 27 January, 2014

ISSN 1749-3463 print/ ISSN 1749-3471

(C) 2014 Artifact 
